\title{
La represión del deseo en el cine cubano
}

\author{
Memorias del subdesarrollo | Cecilia | Fresa y Chocolate \\ Gabriel Guillén* \\ Middlebury Institute of International Studies, Monterey, United States of America
}

Recibido: 16 de diciembre 2016; aceptado: 21 de marzo 2017

\begin{abstract}
Resumen
En este ensayo se estudia la figura del playboy como antihéroe sexual en tres de las películas más representativas del cine cubano, Memorias del subdesarrollo (1968), Cecilia (1981) y Fresa y Chocolate (1994). La censura cinematográfica de estos antihéroes refleja la arquitectura moral de un sistema político que, al menos durante los años 60, trató de "reconducir" la vida íntima de sus ciudadanos, más allá de una lucha legítima y necesaria por la igualdad de género. A través de un análisis en detalle de las tres películas se pretende demostrar que esta represión del deseo traspasa la condena del patriarcado visual y entronca, precisamente, con el cine de Hollywood en su sanción del deseo sexual. Con este estudio no se pone en duda la calidad de las películas. Todo lo contrario, se aprovecha su caudal artístico e ideológico para reflexionar sobre la sexualidad en el arte y en la política de Cuba y comprobar que, a pesar de algunas intenciones tan legítimas como la ironía frente al deseo masculino de la cámara o la integración del homosexual en la Cuba revolucionaria, la represión, contención o condena cinematográfica de Sergio, Leonardo y Diego representan una moral más conservadora que liberal y no tan revolucionaria como burguesa.
\end{abstract}

Palabras clave: cine cubano | sexualidad | cine e ideología

The repression of the desire in Cuban cinema: the sexual antiheroes of Memories of Underdevelopment, Cecilia and Strawberry and Chocolate

\begin{abstract}
This article explores the "playboy" as a sexual antihero in three of the most representative films of Cuban cinema, Memorias del subdesarrollo (1968), Cecilia (1981), and Fresa y Chocolate (1994). The visual censorship of these antiheroes reflects the moral architecture of a political system that, at least during the 1960s, tried to "dictate" the intimate life of its citizens. Through a detailed analysis of the three films, it seeks to demonstrate that this repression of desire transcends the condemnation of a visual patriarchy, joining Hollywood cinema in the sanction of sexual appetite. The repressions of film protagonists Sergio, Leonardo and Diego represent a conservative and bourgeois morality, despite some legitimate intentions such as the irony over the male desire of the camera or the integration of the homosexuality in revolutionary Cuba.
\end{abstract}

Keywords: Cuban cinema | sexuality | cinema and ideology

Tres películas cubanas tan diferentes como Memorias del subdesarrollo (1968), Cecilia (1981) y Fresa y Chocolate (1994) comparten, sin embargo, algunas características comunes. En primer lugar, todas ellas son adaptaciones literarias que, en tres décadas distintas de la revolución -finales de los 60 , principios de los 80 y mediados de los 90- crearon un revuelo considerable por cuestiones artísticas e ideológicas. De hecho, hoy en día suponen puntos de inflexión del cine cubano. Por otra parte, los tres filmes presentan a personajes masculinos con rasgos arquetípicos: Sergio en Memorias del subdesarrollo, Leonardo en Cecilia y Diego en Fresa y Chocolate simbolizan al libertino ocioso de la burgue- sía cubana, un playboy que encuentra placer no tanto en la consumación del asedio sexual como en el proceso de conquista del objeto del deseo. Este ensayo se centra en esto último, la figura del playboy, con énfasis en la carga lúdica del término, prorrogando el estudio de ambigüedades artísticas e ideológicas o el análisis de la recepción de los filmes.

Para el análisis interesa, en concreto, cómo las convenciones del cine cubano pueden reflejar la arquitectura moral de un sistema político que, al menos durante los años 60, trató de "reconducir" la vida sexual de sus ciudadanos, más allá de una lucha legítima y necesaria por la igualdad sexual. Esta suerte de puritanismo, no muy

*gaguillen@miis.edu 
distinto del que se atribuye a Hollywood, al estalinismo, a la ética protestante o a la moral burguesa de la misma sociedad que se pretendía combatir, se traduce en la represión o castigo de las aspiraciones de los libertinos y del deseo improductivo. La condena del libertino ya estaba presente en Marx y Engels: "nuestros burgueses, no contentos con tener a las esposas e hijas de sus proletarios a su disposición, sin dejar de hablar de las prostitutas comunes, obtienen el mayor de los placeres cuando seducen a sus respectivas esposas" (Marx y Engels 1848, p. 41). No obstante, al menos en las películas analizadas, también existe una reivindicación del compromiso amoroso, contraria a la propuesta marxista de abolición de la familia y paralela en el caso de Cecilia a la represión o supresión "narrativa" de la prostitución, como veremos más adelante.

Por otra parte, si bien en este trabajo se analiza la articulación del discurso de represión, en absoluto se intenta hacer apología del playboy como depredador sexual. Tampoco se usa el término "represión" en tanto desplazamiento de ideas inaceptables al subconsciente, sino como conjunto de actos destinados a contener, detener o castigar la libertad sexual. También se usa en sintonía con el pensamiento de Foucault, para el cual la represión es una mascarada del antiguo régimen victoriano, de la moral capitalista del trabajo, o de nosotros mismos, ya que dicha represión forma parte de las relaciones de placer y poder, es decir, el deseo no puede entenderse sin el poder y el poder no puede entenderse sin el deseo: "el placer y el deseo no se anulan o contraponen; se buscan, se solapan, se refuerzan el uno al otro. Están entrelazados por mecanismos complejos y artefactos de excitación e incitación" (Foucault, 1948, p. 48). Veremos, por tanto, cómo el placer de los libertinos no está tanto asociado a la consumación del acto sexual, a la prohibición freudiana, como al juego de las relaciones de poder.

Por último, entendemos que no es necesario establecer una diferencia en el análisis de seductores heterosexuales (Sergio y Leonardo) y homosexuales (Diego) puesto que, a pesar de contar con personalidades y barreras sociales muy distintas, sus motivaciones son similares. El término "homosexual" no deja de ser una construcción aleatoria, como nos recuerda el propio Foucault. Es más, la conexión evidente entre los tres seductores confirma que estos filmes pretender censurar el ocio de la seducción, más que condenar el patriarcado sexual (Mullvey, 1989).

\section{El fracaso de Sergio en Memorias del subdesarrollo}

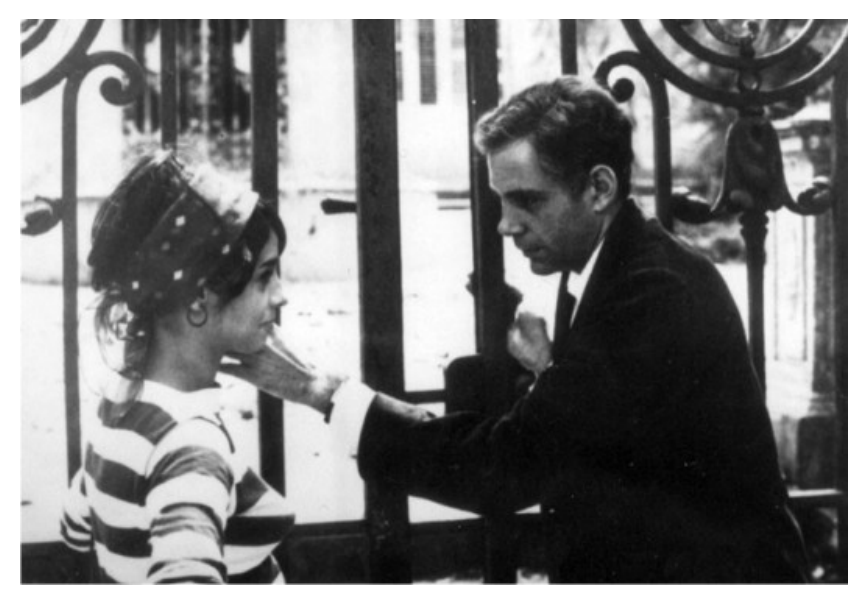

Figura 1. Sergio intenta seducir a Elena

El protagonista de Memorias del subdesarrollo, Sergio (Sergio Corrieri: figura 1), es el prototipo de intelectual escéptico: "la certidumbre es algo para las piedras" (James, 2006, p. 115) confiesa en una entrevista Edmundo Desnoes, autor del libro original y guionista de la película junto a su director, Tomás Gutiérrez Alea. En efecto, Sergio vive en la duda, "alejado de la realidad de Cuba” (Berthier, 2004, p. 570) en una suerte de limbo personal y profesional. Pasea por las calles de La Habana con la misma inutilidad con la que caminan, de forma recurrente, los personajes de El discreto encanto de la burguesía (1972), de Luis Buñuel. El resorte narrativo que activa este vagabundeo mental y físico es, precisamente, la salida de su mujer. Si la identidad del hombre tradicional se asocia al matrimonio (Butler, 1990), Sergio se encuentra varado en las arenas del deseo.

La carencia de un compromiso afectivo, más allá de relaciones esporádicas e imposibles, puede estudiarse como una alegoría a la ausencia de compromiso político. Sergio es un playboy que se obsesiona con la conquista de mujeres a las que cosifica a través de objetos, juegos y un discurso de superioridad. No es extraño, por tanto, que Tomás Gutiérrez Alea, al contrario que Desnoes, no se identifique con el protagonista, tratándolo más bien como a un antihéroe (Berthier, 2004, p. 574). De esta manera, para el espectador, resulta también imposible empatizar con un personaje que, a pesar de su elocuencia, desprecia y asedia a su propia mujer, a la criada de su apartamento burgués, a una estudiante extranjera o a Elena (Daisy Granados), una aspirante a actriz a la que supuestamente desvirga en una maniobra de conquista propia del mito de Don Juan o una película de James Bond. Para él, las mujeres son interesantes en tanto objetos de deseo, los 
cuales pierden su encanto "tropical" (envejecen) con demasiada rapidez.

Las divagaciones intelectuales de Sergio pueden atraer a los que aplauden la ambigüedad existencial como un fin en sí mismo (De la Campa, 1986, 4) pero sus acciones, sus reflexiones sobre las mujeres, sus promesas o actos de habla indirectos, que evitan la incomodidad del conocimiento mutuo (Pinker, 2007, p. 455) están, claramente, destinadas al desprecio del espectador. El filme reproduce el discurso conservador de la misma sociedad occidental a la que se pretende combatir con la revolución: la única salida "feliz" para este playboy que vive de las rentas o plusvalías es comprometerse con una mujer y con la revolución, superando así un paréntesis de decadencia moral, de la misma manera que la salida para Don Juan Tenorio consistía en arrepentirse y abrazar la fe cristiana de la mano de Doña Inés, tal y como sucede al final de la versión de Zorrilla (1844). Memorias del subdesarrollo no proporciona este happy ending moral, en las antípodas del cine en el que cree el guionista Desnoes (James, 2006, p. 112). Sin embargo, la película contiene algunos elementos narrativos que podríamos considerar como inhibidores del deseo sexual.

Primero, la repetición de escenas de conquista amorosa y desnudos sirven para insensibilizar el deseo del espectador. Si en el cine de Hollywood o incluso en algunas películas de la Nouvelle Vague la mirada del espectador frecuentemente se confunde con la mirada de asedio del playboy, en el filme de Alea se establece una ruptura bretchiana con el placer del voyeur. Estas "brechas" no invitan tanto al placer visual como a una reflexión sobre los clichés del lenguaje cinematográfico. Del mismo modo podemos encontrar inhibidores del deseo en la misma narración. Sucede así con las fotografías del bautizo protestante de su criada, las cuales muestran una realidad mucho más prosaica que esa ceremonia sensual sin testigos y con la ropa pegada al cuerpo que Sergio había imaginado previamente; en las peleas contra el hermano y los padres de la chica a la que, supuestamente, ha violado y desvirgado; y en el juicio posterior del que, a pesar de resultar absuelto, sale "mal parado" en palabras del propio protagonista. Sale tan mal parado y es tal su desencanto que sus guionistas se plantearon el suicidio del personaje en la primera versión del guion (Berthier, 2000, p. 574). Sin embargo, finalmente Desnoes y Alea optaron por un final ambiguo más acorde, en nuestra opinión, con el carácter abierto de Memorias del subdesarrollo.

En este punto es importante recordar que la película no intenta predicar, necesariamente, una lección moral con esta escena. Se trata de una película compleja, abierta a distintas interpretaciones y difícil de digerir, como reconoce el propio Alea. Para el director, uno de los efectos positivos de esta sofisticación artística fue hacer que la gente fuera a las salas de cine para ver la película por segunda o tercera vez (Chanan, 2004, p. 302). No obstante, estas "represalias" narrativas representan la oposición de la moral burguesa con la ética de la revolución. La libertad sexual, la vida ociosa del playboy, o el machismo, no tienen espacio en un periodo histórico que requiere un compromiso absoluto con el destino de la revolución. Es un discurso de igualdad, pero también es un discurso de moral burguesa en tanto que se asocia el placer sexual con la improductividad. Por otra parte, como señala Redruello (2006, p. 61), tanto en Memorias del subdesarrollo como en Fresa y chocolate la mujer es visible como objeto de deseo masculino pero invisible como creadora de sentido. Algo parecido expresa Benamou (1994), al señalar el carácter fragmentario de las representaciones femeninas a pesar de la crítica implícita a la cosificación de la mujer en Memorias del subdesarrollo.

\section{El fracaso de Leonardo en Cecilia}

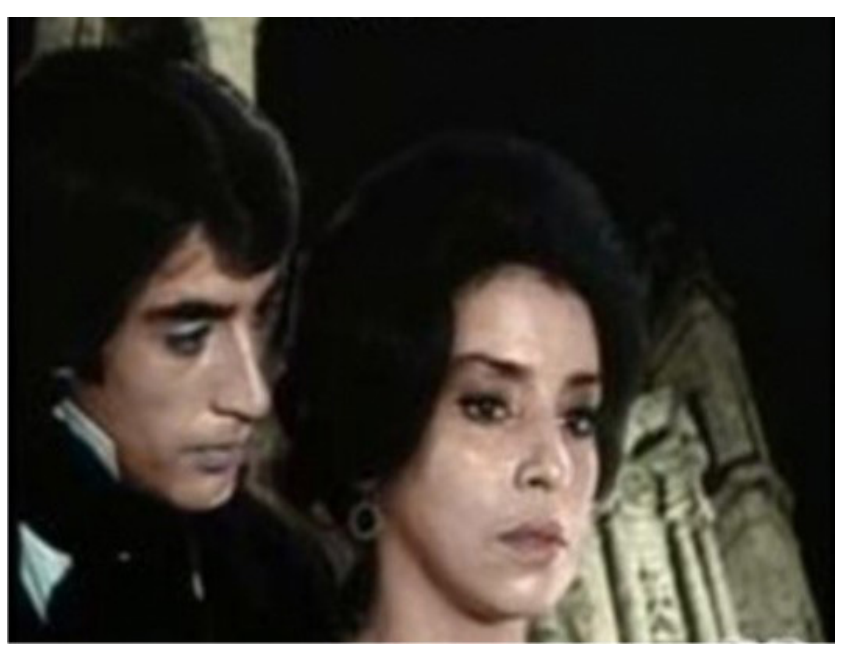

Figura 2. Leonardo intenta seducir a Cecilia

El personaje de Leonardo (Imanol Arias: figura 2) en la Cecilia del director Humberto Solás es, sin duda, menos intelectual y más periférico que el Sergio de Memorias del subdesarrollo, en buena medida porque esta película sí nos ofrece a una mujer, Cecilia (Daisy Granados), como creadora del sentido o, al menos, como elemento vertebrador de la acción narrativa. Sin embargo, pese a 
sus diferencias, ambos personajes masculinos están hechos con el mismo molde. Leonardo, al igual que Sergio, vive de las rentas, con dinero procedente de un ingenio azucarero en el que apenas trabaja, en contra de los deseos de sus padres. Por otra parte, el protagonista masculino de Ceciliaparece sustituir el "compromiso revolucionario" de su época (la lucha contra el esclavismo en la Cuba colonial de 1830) con una conducta de playboy decadente muy similar a la de Sergio en Memorias... y muy distinta a la de Mariano en la propia Cecilia, un criollo independentista y antiesclavista ausente en la novela original Cecilia Valdés.

Esto sería significativo si nuestro objetivo fuera comparar la tasa de compromiso ideológico o estético de ambas narrativas fílmicas. Sin embargo, para el propósito de este ensayo, resulta más relevante ahondar en la vida sexual del criollo Leonardo. Lo conocemos por sus primeras palabras en un baile de la élite habanera, nada más comenzar la película, tras el preludio yoruba y tras una escena polémica en la que Cecilia se masajea el cuerpo con una sensualidad exagerada al tiempo que reclama un blanco a los dioses. Leonardo afirma respecto a Cecilia: "esa sí que es una hembra, Meneses". En respuesta a las dudas de Meneses sobre su inteligencia ("es una estatua", asevera el amigo de Leonardo) añade: "a mí que rayos me importa lo que piense, yo me conformo con lo sabrosa que está, no pido más”.

Como en Memorias del subdesarrollo, la mujer no sólo es el objeto del deseo sino que, además, es un ser inferior en el plano intelectual para el playboy. Su conquista se convierte en la razón de ser de Leonardo. "Desde que te vi en el baile, no hago otra cosa que pensar en ti" añadirá más tarde. El personaje es un "macho cabrío" (en palabras de su escudero de conquistas) que quiere “jugar al juego de los mayores" (en sus propias palabras), esto es, desea perpetuarse en el papel de conquistador de voluntades. Al protagonista masculino no le interesa el "negocio" familiar, el ingenio azucarero, en tanto que es un valor seguro. El "ocio" del playboy es más importante. Leonardo dilapida el dinero en sus "vicios" (en palabras de su padre) que son, sobra decirlo, las mujeres, el juego de la conquista sexual. Como es lógico, el personaje de Imanol Arias en la película también llama al menosprecio del espectador.

¿Cuál es, en el caso de Leonardo, el castigo contra sus engaños y juegos sexuales? El desprecio, la ironía de Cecilia, en recreación indirecta a las bromas de Elena (de nuevo, Daisy Granados) en Memorias del subdesarrollo, anticipan el fracaso del antihéroe. Es cierto que tanto
Cecilia como Leonardo acaban por enamorarse, pero lo hacen enredados en un juego de intereses. El amor y el favor al que accede Leonardo (esconder a un rebelde) son sus agentes de represión. El sexo, siempre inserto en relaciones de poder, se convierte en un elemento al servicio de la sublevación. Leonardo intenta resistirse pero, para él, es más importante el "amor". Es este cambio repentino, sin una evolución clara del personaje, al menos en la versión reducida de la película, el que sin embargo representa la inhibición del antihéroe. Esta inhibición se refuerza, más adelante, con un dilema impropio de un playboy: casarse con Cecilia sin delatar al prófugo o delatarlo y casarse con Isabel (Eslinda Nuñez), perteneciente a su misma clase social. Finalmente, la madre de Leonardo decide traicionar a su hijo, lo cual causa el suicidio de Cecilia y la muerte del mismo Leonardo. No está de más recordar que la película, en lugar de recrear la relación incestuosa entre Leonardo y su hermanastra Cecilia, que se haya en la novela original, insinúa una relación edípica entre Leonardo y su madre para menor gloria del macho nacional, tal y como apunta Chanan (2004):

Es otro elemento que Solás ha introducido con su lectura de la novela; Leonardo es atrapado por una relación idílica con su madre que, a pesar de la interpretación elegante de Imanol Arias, constituye una reconstrucción particularmente problemática del personaje, al convertir al macho tradicional en uno de esos héroes patológicos cuya emergencia fue descrita por Georg Lukács al principio de siglo, como nos recuerda Fredic Jameson (p. 391).

Esta nueva lectura del clásico cubano fue polémica en su momento pero legítima para Caballero y Del Río ("no hay cine adulto sin herejía sistemática"; citado en Chanan, 2004, p. 392) o para el propio director en tanto que es una reinterpretación de un mito con versiones para novela, zarzuela y ballet (Chanan, 2004, p. 393). Del mismo modo, podría considerarse como una estrategia de represión de los asedios sexuales del playboy. ¿Acaso no existe mejor inhibidor del apetito sexual que una relación incestuosa e infantil con la madre, en el marco de esta narrativa freudiana?

Esto se sumaría al mencionado juego de compromisos político-amorosos y al desenlace trágico de la película, el cual representa un castigo de la madre-metrópoli a la corrupción sexual de la colonia, encarnada en la relación problemática del criollo. Obviamente, no parece que el subtexto moral de la película consista en condenar esta relación si bien resulta evidente que la resolución de la película castiga la incertidumbre de Leonardo, quien fue 
incapaz de reaccionar activamente a favor o en contra de la sublevación y de unas represalias más que previsibles por parte de su madre. Esta represión del mundo de sus juegos de conquista amorosa (de relaciones de poder) es, sin duda, similar a la que sufre el intelectual errabundo de Memorias del subdesarrollo.

\section{El fracaso de Diego en Fresa y Chocolate}

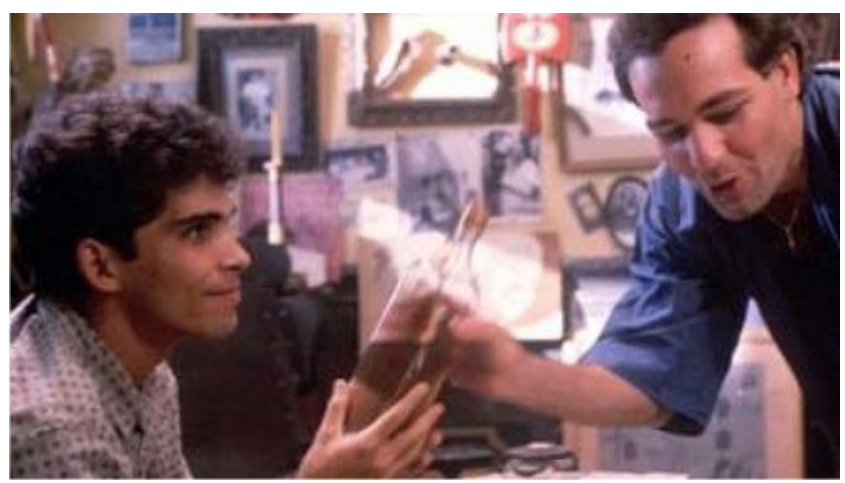

Figura 3. Diego intenta seducir a David

Con el tercero de nuestros seductores, el Diego (Jorge Perugorría: figura 3) de Fresa y Chocolate, es más fácil simpatizar. De hecho, aun poseyendo muchas de las características que eran vistas como negativas en la Cuba socialista (Bejel, 1997, p. 67), Diego es el instrumento de Alea para proponer la integración del homosexual en la revolución. Por esta razón, el personaje "insiste en que él es profundamente nacionalista” (Bejel, 1997, p. 67) a pesar de sus hábitos burgueses, creencias religiosas e identidad sexual contraria a la moral de la Revolución (Smith, 1996). Se argumenta esto último no sólo porque Diego es homosexual sino también porque el personaje se presenta como una suerte de playboy, abstraído de la realidad por el juego de la conquista sexual. Es interesante que, al igual que Sergio y Leonardo, Diego vive una vida mayormente ociosa. Tal y como argumenta Bejel (1997, p. 68), la película hubiera mostrado un mayor compromiso con la causa gay a través de un personaje que fuera campesino o miembro del proletariado. Pero no es así.

Diego es un personaje sofisticado que tiene tiempo para leer y disfrutar de un helado mientras intenta conquistar a David con promesas, mentiras, insinuaciones y actos de habla tan indirectos como los de Sergio en Memorias del subdesarrollo o Leonardo en Cecilia. De esta manera se presenta a David y al espectador con un "no pude resistir la tentación, me encanta la fresa”, al que más tarde añade "hoy es mi día de suerte, me encuentro maravillas". Más tarde, en su apartamento, derramara el café sobre la camisa de David en una maniobra de conquista que, sin duda, lo equipara a sus predecesores Sergio y Leonardo. De hecho, al sacar su camisa al balcón, está enviando una señal de triunfo sexual a Germán, su amigo escultor, con el que había cruzado una apuesta.

Se confirma pues que el placer no está tanto en la consumación de la conquista como en el juego erótico de las relaciones de poder. El personaje de Diego representa al colonizador de la metrópoli que intenta seducir al campesino (proletario) en un juego de seducción muy similar al de Leonardo y Cecilia en la superproducción de Humberto Solás. Del mismo modo, el eurocentrismo de Diego puede asociarse con el de Sergio en Memorias del subdesarrollo (Bejel, 1994, p. 13), al igual que sucede con su sofisticación e intención de educar a David. Por tanto, no es extraño que, a pesar de que el "subtexto" de Fresa y chocolate impide que sea considerada como un puro tratado de la represión, la película contenga tantos o más frenos del deseo como las otras películas mencionadas en este trabajo.

La primera represión es obvia. El filme tiene una lectura tradicional en tanto que reprime o sublima una posible tensión sexual entre Diego y David mediante la apología de su amistad y la relación de David con Nancy (provocada por el mismo Diego). En este sentido, no resulta extraño que David pierda su virginidad con Nancy en la cama de Diego. También es lógico que la propia Nancy, una prostituta, deje la calle para tener una relación tradicional con David. No olvidemos que el marxismo condena la prostitución por su trasfondo de explotación burguesa. De igual forma, la promiscuidad tenía connotaciones negativas en la Revolución. El propio personaje de Diego refleja esa represión en un discurso dicotómico que describe el deber y el sexo como polos opuestos. Pese a que, como hemos argumentado, la película tiene éxito en su mensaje de integración, la reflexión de Diego es, como es natural, fruto de un momento de represión de la sexualidad. Acaso no es extraño que la última palabra de las siglas de las Unidades Militares de Ayuda a la Producción (UMAP), donde acabaron trabajando de forma forzosa muchas de las víctimas del llamado "problema homosexual" de 1965 a 1967, sea precisamente producción.

El sexo sin amor, sin (re)producción, es improductivo, aunque no se acaban aquí las represiones de una película que es mucho menos radical que el cuento. Si este último nos cuenta la primera relación sexual de Die- 
go con detalle, en la película se omite este detalle precisamente porque David, el representante de una moral supuestamente heterosexual, se lo impide: "yo no tengo que oír eso”. Finalmente, la última represión es paradójica puesto que coincide con el clímax de la amistad entre Diego y David. El abrazo de los dos protagonistas en la "guarida" es una obvia llamada a la reconciliación, al igual que el último encuentro, ya sin complejos, en la heladería Coppelia. Sin embargo, en la escena final podemos ver cómo ambos actores se miran a la cara y se detienen momentáneamente antes de fundirse en un abrazo, previo al exilio del protagonista. Era la última oportunidad de Diego, pero el seductor se contiene de la misma forma que los guionistas se contuvieron a la hora de definir la heterosexualidad de David.

No se trata de argumentar que toda relación amistosa esconde una relación sexual (acaso sí de poder y deseo) pero resulta evidente que la película es un producto ideológico. El propio Senel Paz, autor del relato y uno de los guionistas, reconoce en una entrevista con Bejel (citado en 1997, p. 70) que decidieron que David fuera completamente heterosexual para fortalecer el mensaje de empatía con la situación del homosexual en Cuba.
No se puede negar que Fresa y Chocolate es, como recuerda Chanan, tanto una denuncia de la homofobia del Partido Comunista Cubano como una crítica de su estética puritana y de la supresión de voces artísticas "desviadas" (p. 467). Tampoco debemos olvidar que con esta película por primera vez "el cine cubano incorpora al gay como protagonista y como sujeto, tanto dramático como narrativo" (Padrón, 2007, p. 147). Sin embargo, la película es también un reflejo de la moral del Estado, tan inserta en la Revolución (Santi, 1998, p. 422) como sus predecesoras Memorias del subdesarrollo y Cecilia.

Con este análisis de personajes no se pretendió poner en duda la calidad de las películas sino, precisamente, aprovechar su caudal artístico eideológico para reflexionar sobre la sexualidad en el arte y en la política de Cuba. Creemos que se ha comprobado que, a pesar de algunas intenciones tan legítimas como la ironía frente al deseo masculino de la cámara o la integración del homosexual en la Cuba revolucionaria, la represión, contención o condena cinematográfica de Sergio, Leonardo y Diego representan una moral más conservadora que liberal y no tan revolucionaria como burguesa.

\section{Referencias}

Bejel, E. (1994). Fresa y chocolate o la salida de la guardia. Casa de las Américas. 196, 11-22.

Bejel, E. (1997). Strawberry and Chocolate, Coming Out of the Cuban Closet. South Atlantic Quarterly. 46 (1), 66-84

Benamou, C. (1994). Cuban Cinema: On the Threshold of Gender. Journal of Women Studies. 15 (1), 51-75.

Berthier, N. (2004). Cine y revolución: Memorias del subdesarrollo de Tomás Gutiérrez Alea. Anuario del Archivo Histórico Insular de Fuerteventura. 5, 564-575.

Butler, J. (1990). Gender Trouble. Feminism and the subversión of identity. New York: Routledge.

Caballero, R. y J. del Río. (1995). No hay cine adulto sin herejía sistemática. Temas. 3, 102-115.

Chanan, M. (2004). Cuban Cinema. Minneapolis: University of Minessota Press.

De la Campa, R. (1986). Memorias del subdesarrollo: Novela/Texto/Discurso. Hispamérica. 44, 3-18.

Foucault, M. (1978). History of Sexuality. Vol 1: An Introduction. New York: Vintage Books.

Jaimes, H. (2006). Memorias del Desarrollo: El placer de las ruinas (entrevista a Desnoes). Contracorriente. 4 (1): $110-119$.

Marx, K. \& F. Engels. (1906). Manifesto of the Communist Party (1848). Chicago: Charles H. Kerr \& Company.

Mulvey, L. (1989). Visual and other pleasures. Bloomington: Indiana University Press.

Padrón, F. (2007). El gay y otros sujetos semejantes en el audiovisual cubano. Temas.52: 144-154.

Pinker, S. (2007). The evolutionary social psychology of off-record indirect speech acts. Intercultural Pragmatics. 4 (4): $437-461$.

Redruello, L. (2004). “La mujer en el espacio fílmico de Tomás Gutiérrez Alea. La Palabra y el Hombre. 132: 47-61

Rosell, S. (2000). Revisión de mitos en torno a Cecilia y Francisco: de la novela del s. XIX al cine. Hispania. 83 (1): 11-18.

Santi, E. (1998). Fresa y Chocolate: The Rhetoric of Cuban Reconciliation. MLN Hispanic Issue. 113 (2): 407-425.

Smith, P. J. (1996). Vision machines: cinema, literature, and sexuality in Spain and Cuba, 1983-93. London: Verso. 